\title{
Estratégias de Enfrentamento da Pandemia Covid-19 na Alimentação Escolar do Município de Curitiba - PR
}

\author{
Karine Oltramari, ${ }^{1}$ Laís dos Santos, ${ }^{2}$ Juliana Rodrigues Dias Guedes, ${ }^{3}$ \\ Alice Freitas da Silva, ${ }^{4}$ Carolina Sette Barbosa Damasceno, ${ }^{3}$ \\ Liziane Mery Laufer Rodrigues, ${ }^{2}$ Maria Rosi Marques Galvão²
}

\begin{abstract}
RESUMO
Este estudo objetivou descrever as estratégias utilizadas para o fornecimento da alimentação escolar no município de Curitiba, Paraná, Brasil, no contexto do enfrentamento da pandemia ocasionada pelo novo coronavírus no ano de 2020. Esta ação foi pautada primariamente no Direito Humano à Alimentação Adequada e na autorização, em caráter excepcional, da distribuição de gêneros alimentícios aos estudantes de escola pública em todo o país, via Programa Nacional de Alimentação Escolar. O plano de ação utilizado foi a entrega de kits alimentação, cuja composição atendeu às normas vigentes e especificações do Guia Alimentar para a População Brasileira, priorizando alimentos in natura e minimamente processados. Contemplou-se a distribuição de gêneros adquiridos da agricultura familiar e adaptação de alguns alimentos presentes no kit para atendimento das Necessidades Alimentares Especiais. Em maio e junho, respectivamente, foram atendidos 131.703 e 132.562 estudantes matriculados, abrangendo escolas, Centros Municipais de Educação Infantil e Centros de Educação Infantil Contratados. Em resumo, esta ação proporcionou a universalidade do Programa e a garantia de segurança alimentar e nutricional aos estudantes atendidos durante o período de pandemia.
\end{abstract}

Palavras-chave: Epidemia por novo Coronavírus 2019. Estratégias locais. Política nutricional. Segurança alimentar e nutricional. Valor nutricional.

\section{STRATEGIES OF COPING THE COVID-19 PANDEMIA IN THE SCHOOL FEEDING IN CURITIBA CITY, IN PARANA STATE}

\section{ABSTRACT}

This study aimed to describe the strategies used to provide school feeding in Curitiba, Parana, Brazil, in the context of facing the new coronavirus pandemic in 2020. This action was primarily based on the Human Right to Adequate Food and the exceptional authorization of food distribution to public school students throughout the country, by the National School Feeding Program (Programa Nacional de Alimentação Escolar - PNAE). The action plan was to deliver the feeding kits, whose composition met the current standards and specifications of the Food Guide for the Brazilian Population, prioritizing natural and minimally processed foods. The distribution of food purchased from family farming and the adaptation of some foods in the kit to meet the special food needs were contemplated. In May and June, respectively, 131,703 and 132,562 students were attended covering public municipal schools, municipal daycare centers, and contracted daycare centers. In summary, this action reached the program universality and the assurance of food and nutritional security to the attended students during the pandemic period.

Keywords: Coronavírus infections. Local strategies. Nutrition policy. Food and nutrition security. Nutritive value.

RECEBIDO EM: 25/8/2020

MODIFICAÇÕES SOLICITADAS EM: 28/9/2020

ACEITO EM: 6/10/2020

\footnotetext{
Autora correspondente. Prefeitura de Curitiba. Av. Cândido de Abreu, 817 - Centro Cívico, 80530-908, Curitiba/PR, Brasil. http://lattes.cnpq.br/ 5254277248724973.https://orcid.org/0000-0002-1383-1765. karineoltramari@gmail.com

2 Secretaria Municipal de Educação (SME). Curitiba/PR, Brasil.

3 Universidade Federal do Paraná. Curitiba/PR, Brasil.

${ }^{4}$ Universidade Federal de Santa Catarina. Florianópolis/SC, Brasil.
} 


\section{INTRODUÇÃO}

No final de janeiro de 2020 a Organização Mundial da Saúde (OMS) declarou emergência em Saúde Pública de importância internacional, em decorrência da propagação de um novo patógeno, o Coronavírus (Sars-CoV-2), causador da doença Covid-19 (Corona Vírus Disease), fato que levou o Brasil e outros países do mundo a reconhecerem estado de calamidade pública, ocasionando uma série de mudanças na estrutura da sociedade e na convivência entre pessoas (OPAS, 2020; BRASIL, 2020c).

Como forma de conter a infecção e controlar o aumento no número de casos novos, uma das medidas orientadas pelo Ministério da Saúde (MS), por meio da Portaria MS no 356 (BRASIL, 2020d), foi o isolamento social e a quarentena. Tais medidas impactaram diretamente a continuação das aulas presenciais em todas as escolas públicas e privadas brasileiras, levando à suspensão temporária do ano letivo (BRASIL, 2020a, c).

Com a suspensão das aulas nas escolas públicas, muitos estudantes deixaram de receber temporariamente a alimentação escolar, garantida a todo aluno brasileiro matriculado na rede pública de educação básica por meio do Programa Nacional de Alimentação Escolar (PNAE). Além da suspensão das aulas, pela necessidade de isolamento social, muitas atividades cotidianas também foram interrompidas por conta da pandemia, inclusive importantes para a movimentação da economia do país (OLIVEIRA; ABRANCHES; LANA, 2020).

A crise econômica tem impacto direto na manutenção do emprego, do consumo e, consequentemente, na compra e acesso aos alimentos, fatores que podem levar muitas famílias de estudantes brasileiros à situação de vulnerabilidade social, insegurança alimentar e nutricional e à fome (FREITAS; PENA, 2020).

Diante disso, com vistas a assegurar a garantia da alimentação como um direito, previsto pela Constituição Federal no artigo 6 o, e garantir a universalidade do atendimento do PNAE aos estudantes, em abril de 2020 a Lei no 13.987 autorizou, em caráter excepcional, durante o período de suspensão das aulas em razão de situação de emergência ou calamidade pública, a distribuição de gêneros alimentícios adquiridos com recursos do PNAE aos pais ou responsáveis dos estudantes das escolas públicas de educação básica (BRASIL, 2020a).

Para auxiliar as Entidades Executoras (EEx) no processo de execução no PNAE e nas tomadas de decisão durante este período, o Ministério da Educa- ção (MEC) e o Fundo Nacional de Desenvolvimento da Educação (FNDE), por meio da Resolução no 2 de 9 de abril de 2020, recomendaram a distribuição de gêneros alimentícios adquiridos no âmbito do PNAE às famílias dos estudantes a critério do poder público local. Conforme disposto no segundo parágrafo do artigo 2 o da referida resolução, os kits com gêneros alimentícios devem ser elaborados seguindo as determinações legais do PNAE no que se refere à qualidade nutricional e sanitária, respeitando os hábitos alimentares e a cultura local, sendo compostos, sobretudo, por alimentos in natura e minimamente processados, tanto para os gêneros perecíveis quanto para os não perecíveis (BRASIL, 2020d).

Levando-se em consideração os aspectos apresentados, o objetivo do presente trabalho é descrever as estratégias utilizadas para o fornecimento da alimentação escolar no município de Curitiba - PR, durante o enfrentamento da pandemia da Covid-19.

\section{METODOLOGIA}

A Prefeitura de Curitiba - PR (PMC), pela Secretaria Municipal de Segurança Alimentar e Nutricional (SMSAN), em parceria com a Secretaria Municipal de Educação (SME), realizou uma primeira ação imediata no mês de abril de 2020 que consistiu na distribuição do subsídio alimentar no valor de $\mathrm{R} \$ 70,00$ direcionado para as famílias de estudantes matriculados na Rede Municipal de Ensino de Curitiba, e que estivessem cadastradas no Programa Bolsa Família, para aquisição de produtos no Armazém da Família, equipamento público de segurança alimentar e nutricional gerenciado pela SMSAN, que oferece alimentos básicos a preços em média $30 \%$ mais baixos que no mercado.

Logo após esta primeira ação, com aprovação da Lei no 13.987/2020, regulamentada pela Resolução CD/ FNDE no 02/2020, a partir de maio de 2020 foi estruturada uma nova estratégia para a distribuição de gêneros alimentícios adquiridos com recursos do PNAE, por meio de kits de alimentação desenvolvidos pelas nutricionistas lotadas na Gerência de Alimentação do Departamento de Logística da SME, para todos os estudantes da Rede Municipal de Ensino de Curitiba.

Em conformidade com o Decreto Municipal no 604, que dispõe sobre o fornecimento de "kit alimentação" para os pais ou responsáveis das crianças e estudantes matriculados na Rede Municipal de Ensino de Curitiba, durante o período de Pandemia da Covid-19, nos termos que especifica, as nutricionistas definiram a composição do kit referente à alimentação 
escolar (CURITIBA, 2020). Também foram consideradas as Resoluções CD/FNDE no 02/2020 e nº 06/2020, além do Guia Alimentar para a População Brasileira, priorizando alimentos in natura e minimamente processados e respeitando os hábitos alimentares e a cultura local (BRASIL, 2020d; BRASIL, 2020e; BRASIL, 2014b). Quanto às Necessidades Alimentares Especiais (Naes), foram consideradas as patologias mais prevalentes nos estudantes matriculados que necessitavam de adaptação de algum item alimentar presente no kit, sendo ofertados kits sem leite e sem glúten, atendendo às disposições da Lei n. 12.982/2020, que determina a obrigatoriedade de elaboração de cardápios especiais para a alimentação escolar (BRASIL, 2014a).

Segundo a Resolução CD/FNDE no 02/2020, a aquisição de gêneros alimentícios provenientes da agricultura familiar deverá ser mantida, sempre que possível (BRASIL, 2020d). Portanto, para atender essa determinação, as nutricionistas consideraram na elaboração do kit as frutas (maçã convencional e ponkan orgânica), legumes (beterraba e cenoura orgânicas) e os tubérculos (aipim e batata doce orgânicos), que as cooperativas contratadas para entrega de hortifrútis informaram ter disponibilidade nesse período.

Não foram necessários ajustes nos processos de aquisição de alimentos provenientes da agricultura familiar durante o período de suspensão das aulas em razão de situação de calamidade pública, visto que os processos estavam em fase de finalização. No mês de março foram assinados os contratos do chamamento público. No mês de maio, iniciou-se a entrega dos alimentos contratados, que foram utilizados na composição dos kits, priorizando os hortifrútis sazonais disponíveis, evitando assim a perda conforme a safra. Para junho, além dos hortifrutis, também foram adquiridos da agricultura familiar, leite em pó e feijão preto.

No caso dos Centros de Educação Infantil (Ceis) contratados, que são centros particulares com vagas compradas pela PMC, os kits de maio foram compostos pelos alimentos disponíveis no almoxarifado do Departamento de Logística da SME, buscando fornecer um kit semelhante das escolas e Centros Municipais de Educação Infantil (Cemeis) e respeitando as datas de validades. Esgotado o estoque de alimentos, para junho foi realizada aquisição de kits de alimentação específicos para atendimento dos Ceis contratados.

Para todos os kits, optou-se por utilizar somente embalagens íntegras (pacotes fechados) com intuito de evitar o risco de contaminação com o manuseio ou fracionamento dos gêneros alimentícios. Outro ponto considerado foi a utilização de alimentos que não necessitassem de refrigeração, buscando garantir a segurança sanitária dos produtos entregues.

Para o cálculo nutricional dos kits de alimentação foi utilizada a ferramenta de planejamento de cardápios disponibilizada pelo FNDE, Plan PNAE (BRASIL, 2019), considerando os fatores de correção (FC) dos alimentos (ANJOS, 2006). A adequação dos nutrientes ofertados foi expressa em porcentagem, utilizando como base as recomendações presentes na Resolução CD/FNDE n. 06/2020 para atendimento de $70 \%$ das necessidades nutricionais das modalidades creche (1 a 3 anos) e ensino fundamental (6 a 10 anos), que corresponde ao período integral e representam os maiores valores (BRASIL, 2020e).

Aproveitando a oportunidade de trabalhar com a educação alimentar e nutricional, foi elaborado um informativo para ser entregue junto com os kits, abordando questões tais como alimentação saudável, higiene dos alimentos e, para atender a recomendação da Resolução CD/FNDE n. 02/2020, sobre lavagem das embalagens dos alimentos entregues (BRASIL, 2020e).

A estratégia foi discutida com o Conselho de Alimentação Escolar (CAE), o qual foi orientado sobre a necessidade de realizar o acompanhamento da distribuição dos kits de alimentação aos pais ou responsáveis, atentando para a manutenção dos cuidados para evitar o contágio da Covid-19. A definição da forma de acompanhamento ficou a critério do próprio Conselho.

As despesas decorrentes da execução do Decreto Municipal no 604, que dispõe sobre o fornecimento de "kit alimentação" para os pais ou responsáveis das crianças e estudantes, ocorreram à conta das dotações próprias consignadas no orçamento, ficando autorizada a utilização dos recursos do PNAE nos termos do artigo 21-A da Lei Federal n. 11.947, de 16 de junho de 2009, acrescido pela Lei Federal n. 13.987, de 7 de abril de 2020 (BRASIL, 2020a; CURITIBA, 2020).

\section{RESULTADOS}

\section{Montagem dos kits de alimentação}

Os kits foram montados e fornecidos pelas empresas, contratadas por processo licitatório, que atendem à PMC no fornecimento da alimentação escolar. Para montar e fornecer os kits as empresas adquiriram os gêneros alimentícios solicitados pela SME, dentro da pauta do contrato originário, obedecendo às quantidades e descrição; receberam os alimentos provenientes da agricultura familiar adquiridos pela PMC, conforme determinações do FNDE; montaram os kits 
e os entregaram nas unidades escolares, responsabilizando-se pela qualidade físico-química e sanitária dos alimentos, conforme legislação vigente e observando os cuidados para evitar o contágio da Covid-19 durante todo o processo.

No caso dos Ceis contratados, os kits de alimentação de maio foram montados no almoxarifado do Departamento de Logística da SME pelos servidores, respeitando as orientações para evitar o contágio da Covid-19, e em junho foram adquiridos kits de alimentação já montados. O fornecimento dos kits de maio e junho para os Ceis contratados foi realizado pela equipe do almoxarifado.

\section{Características nutricionais dos kits de alimentação}

Buscando atender ao estabelecido no Guia Alimentar para a População Brasileira (BRASIL, 2014) e na legislação vigente, as nutricionistas estruturaram um modelo de kit para a alimentação escolar baseado predominantemente em alimentos in natura e minimamente processados (BRASIL, 2014a; BRASIL, 2020a; BRASIL, 2014b).

Considerando a quantidade de matriculados na Rede Municipal de Ensino de Curitiba e a aquisição de gêneros pela Agricultura Familiar, não seria possível fornecer exatamente os mesmos gêneros perecíveis para todos os atendidos pela estratégia. Dessa forma, buscando manter as características nutricionais do kit fornecido, os itens perecíveis foram organizados por grupo alimentar (frutas, folhosos, legumes, tubérculos) e os kits foram compostos por um item de cada grupo e dois tipos de frutas.

Assim, os kits de alimentação foram compostos por alimentos não perecíveis (base seca) e perecíveis (hortifrútis), sendo em maio: $2 \mathrm{~kg}$ de arroz, $1 \mathrm{~kg}$ de feijão preto, $1 \mathrm{~kg}$ de macarrão, $1 \mathrm{~kg}$ de fubá, $1 \mathrm{~kg}$ de farinha de mandioca, uma unidade de óleo de soja, dois pacotes de leite em pó, $1 \mathrm{~kg}$ de sal, $1 \mathrm{~kg}$ de tubérculo (batata doce ou aipim), $1 \mathrm{~kg}$ de legume (cenoura ou beterraba), $2 \mathrm{~kg}$ de frutas ( $1 \mathrm{~kg}$ de ponkan e $1 \mathrm{~kg}$ maçã) e um maço de folhoso (acelga, repolho ou alface). Para o kit de junho foram realizadas pequenas alterações, como retirada do sal e do folhoso, aumento da quantidade de leite em pó, sendo $1 \mathrm{~kg}$ para estudantes das escolas e 1,4 kg para as crianças dos Centros Municipais de Educação Infantil (CMEIS), e inclusão de um pacote de bolacha maisena; os demais itens foram mantidos. Levando em consideração a Lei no $12.982 / 2014$, os kits foram adaptados com leite de soja e biscoito sem leite, e com macarrão de arroz, biscoito sem glúten, farinha de mandioca e fubá de milho sem traços de glúten para atendimento, respectivamente, das duas principais restrições alimentares cadastradas e apresentadas pelos estudantes, dietas sem leite e sem glúten (BRASIL, 2014a).

A composição dos kits de alimentação para os Ceis contratados foi semelhante das escolas e CMEIS, porém, em razão da logística diferenciada de aquisição e fornecimento, ficou restrita a alimentos não perecíveis. Em maio os kits foram compostos pelos alimentos disponíveis no almoxarifado, incluindo $5 \mathrm{~kg}$ de arroz, 1 kg feijão, 1 kg macarrão, 1 kg leite em pó, uma unidade de óleo, margarina ou molho de tomate, $1 \mathrm{~kg}$ de fubá, quirera ou farinhas de mandioca ou milho, um frasco de suco de fruta (laranja ou uva) ou caixa de chá e um pacote de biscoito (doce ou salgado), respeitando as datas de validades. Em junho, os kits foram compostos por: $2 \mathrm{~kg}$ de arroz, $1 \mathrm{~kg}$ de feijão preto, 0,5 kg de macarrão, $1 \mathrm{~kg}$ de fubá, $1 \mathrm{~kg}$ de farinha de trigo, 1 kg de açúcar, uma unidade de óleo de soja, um pacote de leite em pó e duas latas de sardinha em óleo comestivel.

Quanto ao valor nutricional, os kits de alimentação atenderam além das necessidades nutricionais mínimas para todas as modalidades da Rede Municipal de Ensino de Curitiba, inclusive aquelas com permanência em tempo integral, conforme as recomendações previstas na Resolução CD/FNDE n 06/2020. Somente para as crianças dos Ceis contratados no mês de junho, as quantidades de alguns micronutrientes ficaram aquém das recomendações. A composição nutricional dos kits e a adequação dos nutrientes fornecidos estão apresentadas nas Tabelas 1, 2 e 3.

\section{Estratégia de educação alimentar e nutricional}

O informativo elaborado para ser entregue junto com os kits de alimentação, aproveitando a oportunidade de trabalhar a educação alimentar e nutricional, foi feito no formato de fôlder. Esse documento abrangeu uma pequena carta acolhedora e explicativa informando sobre o kit de alimentação e reforçando a importância do cuidado com a saúde; dicas importantes sobre a alimentação, incluindo a higienização das embalagens, higienização dos alimentos, organização e armazenamento correto dos alimentos e dicas consumo, que foi apresentado em forma de esquema, adaptado a partir do guia para uma alimentação saudável em tempos de Covid-10, elaborado pela Associação Brasileira de Nutrição (Asbran) (ASBRAN, 2020); e dicas de como manter uma alimentação saudável. 
Tabela 1 - Composição nutricional e adequação dos nutrientes dos Kits de Alimentação entregues aos estudantes das escolas da Rede Municipal de Ensino de Curitiba durante a suspensão das aulas em razão da pandemia da Covid-19 nos meses de maio e junho. Curitiba, Paraná, Brasil, 2020

\begin{tabular}{lccccc}
\hline \multicolumn{1}{c}{ Nutriente } & PNAE* & Maio & Adequação (\%) & Junho & Adequação (\%) \\
\hline Energia (kcal) & 1.150 & 1.691 & 147 & 1.712 & 149 \\
Proteína (g) & $30-43$ & 38 & 88 a 127 & 39 & 91 a 130 \\
\% VET & 10 a 15 & 9 & & 9 & 153 a 305 \\
Lipídios (g) & $19-38$ & 56 & 147 a 295 & 58 & 135 a 159 \\
\% VET & 15 a 30 & 30 & & 30 & 260 \\
Carboidratos (g) & $164-193$ & 261 & 135 a 159 & 61 & \\
\% VET & 55 a 65 & 61 & & & \\
\hline
\end{tabular}

VET: Valor Energético Total da dieta.

* Resolução 6 de 08 de maio de 2020, 70\% das necessidades nutricionais diárias para modalidade Ensino Fundamental - faixa etária de 6 a 10 anos

Tabela 2 - Composição nutricional e adequação dos nutrientes dos Kits de Alimentação entregues aos estudantes dos CMEIS da Rede Municipal de Ensino de Curitiba durante a suspensão das aulas em razão da pandemia da Covid-19 nos meses de maio e junho. Curitiba, Paraná, Brasil, 2020

\begin{tabular}{|c|c|c|c|c|c|}
\hline Nutriente & PNAE* & Maio & Adequação (\%) & Junho & Adequação (\%) \\
\hline Energia (kcal) & 897 & 1691 & 189 & 1806 & 201 \\
\hline Proteína (g) & 22,5 a 34,5 & 38 & 110 a 169 & 43 & 125 a 191 \\
\hline$\%$ VET & 10 a 15 & 9 & & 10 & \\
\hline Lipídios (g) & 15 a 29,9 & 56 & 187 a 373 & 63 & 211 a 420 \\
\hline$\%$ VET & 15 a 30 & 30 & & 31 & \\
\hline Carboidratos (g) & 123 a 146 & 261 & 179 a 212 & 268 & 184 a 218 \\
\hline$\%$ VET & 55 a 65 & 61 & & 59 & \\
\hline Cálcio (mg) & 350 & 501 & 143 & 693 & 198 \\
\hline Ferro (mg) & 2,1 & 5,8 & 276 & 5,7 & 271 \\
\hline Retinol (mcg) & 147 & 138 & 94 & 230 & 156 \\
\hline Vitamina C (mg) & 9,1 & 47,4 & 521 & 24,7 & 271 \\
\hline
\end{tabular}

CMEIS: Centros Municipais de Educação Infantil.

* Resolução 6 de 8 de maio de 2020, 70\% das necessidades nutricionais diárias para modalidade creche - faixa etária de 1 a 3 anos.

Tabela 3 - Composição nutricional e adequação dos nutrientes dos Kits de Alimentação entregues aos estudantes dos Ceis contratados da Rede Municipal de Ensino de Curitiba durante a suspensão das aulas em razão da pandemia da Covid-19 nos meses de maio e junho. Curitiba, Paraná, Brasil, 2020

\begin{tabular}{|c|c|c|c|c|c|}
\hline Nutriente & PNAE* & Maio & Adequação (\%) & Junho & Adequação (\%) \\
\hline Energia (kcal) & 897 & 1.676 & 187 & 1.534 & 171 \\
\hline Proteína (g) & 22,5 a 34,5 & 45 & 130 a 200 & 32 & 93 a 142 \\
\hline$\%$ VET & 10 a 15 & 11 & & 8 & \\
\hline Lipídios (g) & 15 a 29,9 & 48 & 161 a 320 & 51 & 171 a 340 \\
\hline$\%$ VET & 15 a 30 & 26 & & 30 & \\
\hline Carboidratos (g) & 123 a 146 & 261 & 179 a 212 & 237 & 162 a 193 \\
\hline$\%$ VET & 55 a 65 & 62 & & 62 & \\
\hline Cálcio (mg) & 350 & 523 & 149 & 292 & 83 \\
\hline Ferro (mg) & 2,1 & 6,4 & 305 & 5 & 238 \\
\hline Retinol (mcg) & 147 & 213 & 145 & 66 & 45 \\
\hline Vitamina C (mg) & 9,1 & 28,4 & 312 & 0 & 0 \\
\hline
\end{tabular}

Ceis contratados: Centros de Educação Infantil contratados.

* Resolução 6 de 8 de maio de 2020, 70\% das necessidades nutricionais diárias para modalidade creche - faixa etária de 1 a 3 anos. 


\section{Distribuição dos kits de alimentação}

A distribuição dos kits de alimentação foi realizada nas unidades escolares, conforme cronograma estabelecido, que aproveitou o momento da entrega de atividades pedagógicas predefinidas. As entregas foram escalonadas a fim de atender às recomendações do Ministério da Saúde e da Resolução CD/FNDE no 2/2020, quanto a evitar aglomerações (BRASIL, 2020b; BRASIL, 2020d). Durante a distribuição dos kits foram coletadas as assinaturas dos pais ou responsáveis, em documento específico, para comprovação do recebimento do kit e posterior prestação de contas.

Levando-se em consideração o momento de pandemia em virtude da Covid-19, os diretores das unidades escolares foram orientados a atender, na distribuição dos kits, às recomendações de higienização das mãos, paramentação da equipe, limpeza e desinfecção de superfícies, demarcação do distanciamento adequado, exigência do uso de máscara e orientação quanto à higienização das mãos aos pais e/ou responsáveis pelos estudantes.

\section{Número de beneficiários}

A PMC, por meio da SME, atendeu à clientela composta por 131.703 e 132.562 estudantes matriculados, respectivamente, nos meses de maio e junho, abrangendo escolas, CMEIS e Ceis Contratados. Todos os estudantes foram considerados na estratégia, porém nem todas as famílias desejaram receber os kits de alimentação. Pensando nisso, foram realizadas pesquisas de interesse para levantamento do número de kits a ser enviado para cada unidade escolar para serem entregues às famílias dos estudantes. No total foram entregues 113.477 kits de alimentação (86,16\% de atendimento) em maio e 120.536 (90,93\%) em junho. É possível observar que houve um aumento no número de famílias que foram retirar o kit em junho (Tabela 4).

Menor número de famílias (em relação ao número enviado às unidades) foi retirar os kits de alimentação, resultando em sobras de alguns kits, os quais foram recolhidos pelas empresas contratadas, responsáveis pela entrega às unidades. A parte não perecível do kit que sobrou foi devolvida para as empresas e não foi paga, na medida em que a parte perecível foi adquirida com recursos próprios municipais e doados para a Fundação de Ação Social (FAS) da PMC, buscando, assim, evitar o desperdício de alimentos e otimizar os recursos públicos. Em relação aos Ceis Contratados, os kits que não foram entregues às famílias foram recolhidos pelo almoxarifado.

\section{DISCUSSÃO}

A alimentação escolar compreende todo alimento oferecido no ambiente escolar e toda a alimentação realizada pelo estudante durante o período em que se encontra na escola. Com a suspensão das aulas presenciais e após a autorização da distribuição dos gêneros alimentícios aos pais e/ou responsáveis pelos estudantes, o maior desafio foi essa quebra de paradigmas, uma vez que o alimento não seria mais consumido em ambiente escolar.

Os direitos humanos são inerentes a todas as pessoas e devem ser assegurados por políticas públicas que favoreçam o seu pleno exercício, e que permi-

Tabela 4 - Números de estudantes matriculados Rede Municipal de Ensino de Curitiba durante a suspensão das aulas em razão da pandemia da Covid-19 e número de kits de alimentação entregues nos meses de maio e junho. Curitiba, Paraná, Brasil, 2020

\begin{tabular}{llccc}
\hline & & Maio & Junho & \% de variação \\
\hline Matrículas $(\mathrm{n})$ & Geral & 131.703 & 132.562 & 0,65 \\
& Escolas & 93.854 & 94.635 & 0,83 \\
& CMElS & 30.671 & 30.749 & 0,25 \\
Kits entregues $(\mathrm{n})$ & Ceis contratados & 7.178 & 7.178 & 0,00 \\
& Geral & 113.477 & 120.536 & 6,22 \\
& Escolas & 79.674 & 85.661 & 7,51 \\
& CMEIS & 28.184 & 29.167 & 3,49 \\
Atendimento (\%) & Ceis contratados & 5.618 & 5.708 & 1,60 \\
& Geral & 86,16 & 90,93 & 4,77 \\
& Escolas & 84,89 & 90,52 & 5,63 \\
& CMElS & 91,89 & 94,86 & 2,97 \\
& Ceis contratados & 78,27 & 79,52 & 1,25 \\
\hline
\end{tabular}

CMEIS: Centros Municipais de Educação Infantil; Ceis Contratados: Centros de Educação Infantil Contratados. 
tam a todo o ser humano condições básicas para viver de forma digna (LEÃO, 2013). A garantia dos direitos humanos, incluindo o Direito Humano à Alimentação Adequada (DHAA), foi conquistada por meio de muitas lutas e movimentos sociais ao longo do tempo. No Brasil, o direito à alimentação está assegurado desde 2010 pela Constituição Federal, com a aprovação da Emenda Constitucional no 64. O DHAA é considerado pressuposto para a sobrevivência e pré-requisito para a realização de outros direitos humanos (LEÃO, 2013). Muitas pessoas no Brasil e no mundo, entretanto, ainda não estão livres da fome e vivem em situação de insegurança alimentar, o que foi intensificado e agravado com a pandemia do Coronavírus (Sars-CoV-2) durante parte do ano 2020 (LEÃO, 2013; FREITAS; PENA, 2020).

A garantia da segurança alimentar e nutricional constitui um grande desafio em tempos de pandemia, sobretudo com a desarticulação e enfraquecimento de órgãos importantes nesse contexto, como o ConseIho Nacional de Segurança Alimentar (Consea), recentemente extinto. Por outro lado, a crise gera mecanismos de adaptação adotados pelos cidadãos, os quais incluem mudanças alimentares. Há uma tendência no aumento da aquisição de alimentos processados e ultraprocessados como forma de se proteger de uma possível escassez, à medida que hortifrutis frescos se tornam menos disponíveis (OLIVEIRA; ABRANCHES; LANA, 2020). Além disso, problemas crônicos, como obesidade, doenças não transmissíveis e carências nutricionais, provavelmente aumentarão em razão da combinação de acesso limitado a alimentos de qualidade, más escolhas alimentares e diminuição da prática de exercícios físicos, agravando o impacto da doença (OLIVEIRA; ABRANCHES; LANA, 2020; ZURAYK, 2020).

A deficiência ou inadequação do estado nutricional está associada ao comprometimento da função imunológica, contribuindo para o aumento da morbidade e mortalidade por infecções, assim como sua boa atuação favorece as defesas na prevenção ou recuperação de infecções (LARBI; CEXUS; BOSCO, 2018). Dessa forma, a boa nutrição é um fator significativo na determinação do estado de saúde e longevidade, e isso envolve a compreensão da importância de uma alimentação adequada e equilibrada que evolui com o tempo, sendo influenciada por diversos fatores sociais e econômicos que interagem de maneira complexa para moldar os padrões alimentares individuais (OPAS, 2019).
No Brasil, assim como em outros países, a alimentação escolar como política pública surgiu a partir da necessidade de o Estado solucionar o problema da fome, que já na primeira metade do século 20 era associada à pobreza extrema no país (TURPIN, 2008). Assim, o PNAE é umas das políticas públicas de segurança alimentar e nutricional mais antigas do país, e considerado um dos maiores programas de alimentação escolar do mundo (VASCONCELOS, 2013).

Nesse sentido, a criação do PNAE em 1954, formalizada em 1955 por meio do Decreto no 37.106/55 do então Ministério da Educação e Cultura, tinha como um de seus principais objetivos a redução de doenças nutricionais relacionadas à fome e à miséria, como a desnutrição infantil, muito comum na época (TURPIN, 2008; VASCONCELOS, 2013). Com o passar o tempo, o PNAE tornou-se cada vez mais abrangente, deixando de apresentar um caráter assistencialista, e configurando-se, por meio da Lei no 11.947 de 2009, como uma das principais estratégias para garantir o DHAA nas escolas, priorizando o desenvolvimento biopsicossocial, o rendimento escolar, a formação de hábitos alimentares saudáveis dos escolares, além da oferta de refeições que atendam às necessidades nutricionais dos estudantes, inclusive com alimentos oriundos da agricultura familiar (BRASIL, 2009; SILVA; AMPARO-SANTOS; SOARES, 2018).

Em abril de 2020, pela primeira vez na história do PNAE, por conta da Pandemia de Covid-19, foi autorizada, em caráter excepcional, a distribuição de gêneros alimentícios adquiridos com recursos do programa aos pais ou responsáveis dos estudantes das escolas públicas de educação básica durante o período de suspensão das aulas (BRASIL, 2014a; BRASIL, 2020b). Com essa importante medida, os estudantes passaram a receber alimentos corriqueiramente consumidos na escola para serem consumidos em seus lares. De acordo com Silva, Amparo-Santos e Soares (2018), o ato de alimentar-se na escola é relevante e configura-se como um importante fator que influencia a construção de hábitos alimentares e de identidades de crianças e adolescentes, processo que foi abruptamente interrompido pela situação de calamidade de saúde pública.

Apesar, entretanto, da interrupção das trocas de experiências em ambiente escolar, em cenário de pandemia, é imprescindível haver respostas coordenadas e medidas destinadas a diminuir problemas relacionados à alimentação que sejam compatíveis com a situação de calamidade pública, bem como ações que reforcem as redes de segurança alimentar e nutricional, sobretudo para atender à população mais 
vulnerável. A adoção de um programa emergencial de distribuição de kits contendo alimentos básicos à população atendida por programas de alimentação escolar, articulando estratégias de compra de itens produzidos regionalmente, além de garantir acesso à alimentação, garante renda via geração de emprego e provê grande auxílio aos agricultores com dificuldade de escoamento de seus produtos. O aproveitamento do desenho institucional das políticas de compras institucionais da agricultura familiar fortalece a segurança alimentar e nutricional no campo e na cidade (ARRAIS, 2020; COMISIÓN..., 2020).

A fim de garantir o fornecimento de itens da agricultura familiar aos estudantes por meio de kits de alimentação, o próprio FNDE aponta novas formas de execução durante a pandemia, apresentando como estratégia a continuidade da compra da agricultura familiar e a elaboração da chamada pública eletrônica, contemplando todas as etapas referentes ao processo de aquisição e finalizando com o contrato de compra e venda. É muito importante que ocorra manutenção dos contratos firmados com os agricultores familiares, respeitando o calendário de entrega já estipulado, de modo que o agricultor não seja onerado (BRASIL, 2020b).

Embora diversos municípios brasileiros estejam, de alguma forma, realizando ações para o enfrentamento da pandemia com respeito à alimentação escolar, os relatos sobre essas ações ainda são incipientes. De acordo com Diniz, Silva e Guerci (2020), entre as iniciativas envolvendo economia popular urbana, prefeituras de municípios da região metropolitana de Belo Horizonte (MG) realizaram a distribuição de cestas básicas a famílias de estudantes de escolas públicas. A maneira como ocorreu essa ação, no entanto, não foi relatada.

Em algumas capitais, como São Paulo (SP) e Rio de Janeiro (RJ), foram distribuídos "cartões alimentação" às famílias de estudantes para compra de gêneros alimentícios, visando a garantir o acesso à alimentação durante o período de suspensão de aulas (SÃO PAULO, 2020; RIO DE JANEIRO, 2020). A prefeitura do Rio de Janeiro (RJ) justificou a escolha pelo repasse da alimentação em forma de benefício por considerar a entrega de kits de alimentação complexa do ponto de vista da logística (RIO DE JANEIRO, 2020).

Em outros municípios como Manaus (AM) e Goiânia (GO), assim como em Curitiba (PR) na segunda estratégia, foram distribuídos kits de alimentação a todos os estudantes de suas respectivas redes municipais de ensino (GOIÂNIA, 2020, MANAUS, 2020). No Norte do Brasil, a Prefeitura de Manaus (AM) be- neficiou mais de 242 mil estudantes por meio projeto "Hora da Merenda", ação na qual os kits alimentícios foram entregues às famílias dos estudantes tanto da zona urbana quanto rural da capital amazonense (MANAUS, 2020). Já a Prefeitura de Goiânia (GO) propôs-se a realizar a distribuição dos kits para os mais de 100 mil estudantes da capital, mediante a utilização do cartão PNAE, repassados aos diretores das unidades de ensino que realizavam compras, em mercados locais, dos gêneros alimentícios destinados aos kits (GOIÂNIA, 2020).

A PMC tem conseguido atender de forma universal os estudantes da Rede Municipal de Ensino com o fornecimento de kits de alimentação que suprem as necessidades nutricionais e são compostos, predominantemente, por alimentos in natura e minimamente processados, com gêneros alimentícios provenientes da agricultura familiar, incluindo orgânicos, podendo, assim, contribuir para a segurança alimentar e nutricional dos estudantes durante o período de pandemia.

É relevante levar em consideração que a rede pública de ensino está presente em todo o território nacional com as suas multipluralidades, diferenças e desigualdades significativas. Assim, as ações relatadas neste artigo não servem de modelo de ação, mas, sim, de incentivo para a realização de ações adaptadas a cada realidade. Ainda, destaca-se a importância de relatar, por via científica e acadêmica, as ações realizadas, de modo a auxiliar no processo de construção do estado da arte de um momento tão singular.

\section{CONCLUSÃO}

A estratégia utilizada contemplou todas as diretrizes do PNAE, distribuindo gêneros alimentícios básicos, seguros e que fazem parte da cultura e hábitos alimentares; utilizando estratégia de educação alimentar e nutricional também para as famílias, além do conteúdo curricular; mantendo a universalidade do Programa; contando com o acompanhamento do CAE (controle social) nas ações realizadas; promovendo a aquisição de produtos da agricultura familiar; e garantindo a segurança alimentar e nutricional de forma igualitária, respeitando as condições de saúde dos estudantes portadores de Naes.

\section{FINANCIAMENTO E CONFLITOS DE INTERESSE}

A pesquisa refere-se à estratégia utilizada pela Prefeitura de Curitiba (PR) para o enfrentamento da pandemia da Covid-19 no âmbito da alimentação escolar, cumprindo as regulamentações do PNAE. Não 
houve fonte de financiamento para a realização do estudo e os autores declaram que não há conflitos de interesse.

\section{REFERÊNCIAS}

ANJOS, M. C. R. Relação de fatores de correção e índice de Conversão (cocção) de alimentos. 2006. 11 f. Disponível em: https://docs.ufpr.br/ monica.anjos/Fatores.pdf. Acesso em: 15 jun. 2020.

ARRAIS, T. A. et al. Pandemia Covid-19: o caráter emergencial das transferências de renda direta e indireta para a população vulnerável do estado de Goiás. Espaço e Economia: Revista Brasileira de Geografia Econômica, [S.I.], ano 9, n. 18, 2020. DOI: https://doi.org/10.4000/espacoeconomia.13734.

ASBRAN. Associação Brasileira de Nutrição. Guia para uma alimentação saudável em tempos de Covid-19, São Paulo, 2020.

BRASIL. Lei no 11.947, de 16 de junho de 2009. Dispõe sobre $o$ atendimento da alimentação escolar e do Programa Dinheiro Direto na Escola aos alunos da educação básica. Diário Oficial da União, Brasília, DF, seção 1, 17 jun. 2009.

BRASIL. Lei $n=12.982$, de 28 de maio de 2014. Altera a Lei no 11.947 , de 16 de junho de 2009, para determinar o provimento de alimentação escolar adequada aos alunos portadores de estado ou de condição de saúde específica. Diário Oficial da União, Brasília, DF, 29 maio 2014a.

BRASIL. Lei $n=13.987$, de 7 de abril de 2020. Altera a Lei $n$ ㅇ 11.947, de 16 de junho de 2009, para autorizar, em caráter excepcional, durante o período de suspensão das aulas em razão de situação de emergência ou calamidade pública, a distribuição de gêneros alimentícios adquiridos com recursos do Programa Nacional de Alimentação Escolar (PNAE) aos pais ou responsáveis dos estudantes das escolas públicas de educação básica. Diário Oficial da União, Brasília, DF, edição 67, seção 1, p. 9, 7 abr. 2020a.

BRASIL. Ministério da Agricultura, Pecuária e Abastecimento. Secretaria de Agricultura Familiar e Cooperativismo. Departamento de Cooperativismo e Acesso e Abastecimento. Orientações para a execução do PNAE durante a situação de emergência decorrente da pandemia do Coronavírus (Covid-19). Brasília, DF, 2020b.

BRASIL. Ministério da Educação. Fundo Nacional de Desenvolvimento da Educação. Plan PNAE - Ferramenta de planejamento de cardápio. Brasília, DF, 2019. Disponível em: https://www.fnde.gov.br/index.php/programas/pnae/ pnae-area-gestores/ferramentas-de-apoio-ao-nutricionista/item/12820-plan-pnae-ferramenta-de-planejamento-de-card\%C3\%A1pio. Acesso em: 22 dez. 2019.

BRASIL. Ministério da Saúde. Secretaria de Atenção à Saúde. Departamento de Atenção Básica. Guia alimentar para a população brasileira. 2. ed. Brasília, DF, 2014b.

BRASIL. Portaria no 356, de 11 de março de 2020. Dispõe sobre a regulamentação e operacionalização do disposto na Lei no 13.979, de 6 de fevereiro de 2020, que estabelece as medidas para enfrentamento da emergência de saúde pública de importância internacional decorrente do coronavírus (Covid-19). Diário Oficial da União, Brasília, DF, edição 49, seção 1, p. 185, 12 mar. 2020c.

BRASIL. Resolução no 2, de 9 de abril de 2020. Dispõe sobre a execução do Programa Nacional de Alimentação Escolar PNAE durante o período de estado de calamidade pública, reconhecido pelo Decreto Legislativo $n$ ㅇ 6, de 20 de março de 2020, e da emergência de saúde pública de importância internacional decorrente do novo coronavírus - Covid-19. Diário Oficial da União, Brasília, DF, edição 70, seção 1, p. 27, 13 abr. 2020d.

BRASIL. Resolução no 26, de 17 de junho de 2013. Dispõe sobre o atendimento da alimentação escolar aos alunos da educação básica no âmbito do Programa Nacional de Alimentação Escolar - PNAE. Diário Oficial da União, Brasília, DF, edição 115, seção 1, p. 7, 18 jun. 2013.

BRASIL. Resolução no 6, de 8 de maio de 2020. Dispõe sobre o atendimento da alimentação escolar aos alunos da educação básica no âmbito do Programa Nacional de Alimentação Escolar - PNAE. Diário Oficial da União, Brasília, DF, edição 89, seção 1, p. 38, 12 maio 2020e.

COMISIÓN ECONÓMICA PARA AMÉRICA LATINA. Sistemas alimentarios y Covid-19 en América Latina y el Caribe: plan de contingencia ante una eventual crisis en el abastecimiento de alimentos. Boletín, Santiago do Chile, n. 6, jun. 2020. Disponível em: https://www.cepal.org/es/publicaciones/ 45652-sistemas-alimentarios-covid-19-america-latina-caribe-ndeg-6-plan-contingencia. Acesso em: 10 ago. 2020.

CURITIBA. Prefeitura. Decreto Municipal no 604, de 7 de maio de 2020. Dispõe sobre o fornecimento de "kit alimentação" para os pais ou responsáveis das crianças e estudantes matriculados na Rede Municipal de Ensino, durante o período de Pandemia de Covid-19, nos termos que especifica. Curitiba, 2020.

DINIZ, S. C.; SILVA, G. L.; GUERCI, M. R. Economia popular urbana e o Covid-19: desafios e propostas para a Região Metropolitana de Belo Horizonte. Belo Horizonte: Universidade Federal de Minas Gerais, 2020. Nota técnica - Cedeplar.

FREITAS, M. C. S.; PENA, P. G. L. Fome e pandemia de Covid-19 no Brasil. Tessituras: Revista de Antropologia e Arqueologia, Pelotas, v. 8, n. 1, p. 34-40, 2020.

GOIÂNIA. Prefeitura. SME inicia distribuição da terceira remessa de kits de alimentação. 2020. Notícias. Disponível em: https://www.goiania.go.gov.br/sme-inicia-distribuicao-da-terceira-remessa-de-kits-de-alimentacao/. Acesso em: 12 jul. 2020.

LARBI, A.; CEXUS, O.; BOSCO, N. Nutrition as a tool to reverse immunosenescence? In: CHATTERJEE, S.; JUNGRAITHMAYR, W.; BAGCHI, D. (ed.). Immunity and Inflammation in Health and Disease. Cambridge: Elsevier, 2018. p. 319337.

LEÃO, M. (org.). O direito humano à alimentação adequada e o sistema nacional de segurança alimentar e nutricional. Brasília, DF: ABRANDH, 2013. 
MANAUS. Prefeitura. Entrega dos kits do projeto "Hora da Merenda" nas escolas é encerrada. Manaus, 2020. Notícias. Disponível em: http://www.manaus.am.gov.br/noticia/kits-hora-merenda-encerrada/. Acesso em: 12 ago. 2020.

OLIVEIRA, T. C.; ABRANCHES, M. V.; LANA, R. M. (In)Segurança alimentar no contexto da pandemia por Sars-CoV-2. Cad. Saúde Pública, v. 36, n. 4, p. e00055220, 2020. DOI: 10.1590/0102-311x00055220.

OPAS. Organização Pan-Americana da Saúde. Folha Informativa Alimentação Saudável. 12 jun. 2019. Disponível em: https://www.paho.org/bra/index.php?option=com_content\&view=article\&id=5964:folha-informativa-alimentacao-saudavel\&Itemid=839. Acesso em: 12 ago. 2020.

OPAS. Organização Pan-Americana da Saúde. OMS declara emergência de saúde pública de importância internacional por surto de novo coronavírus. 2020. Disponível em: https://www.paho.org/bra/index.php?option=com_content\&view=article\&id=6100:oms-declara-emergencia-de-saude-publica-de-importancia-internacional-em-relacao-a-novo-coronavirus\&Itemid=812. Acesso em: 12 ago. 2020.

RIO DE JANEIRO. Prefeitura. Cartão alimentação será ampliado e beneficiará todos os alunos da rede pública municipal. Rio de Janeiro, 7 jul. 2020. Notícias. Disponível em: https://prefeitura.rio/educacao/cartao-alimentacao-sera-ampliado-e-beneficiara-todos-os-alunos-da-rede-publica-municipal/. Acesso em: 12 ago. 2020.

SÃO PAULO. Secretaria Municipal de Educação. Prefeitura de São Paulo irá repassar $R \$ 24$ milhões para famílias adquirirem alimentos em casa. São Paulo, 2 abr. 2020. Notícias. Disponível em: https://educacao.sme.prefeitura.sp.gov.br/ prefeitura-de-sao-paulo-ira-repassar-r-24-milhoes-para-familias-adquirirem-alimentos-em-casa/. Acesso em: 12 ago. 2020.

SILVA, E. O.; AMPARO-SANTOS, L.; SOARES, M. D. Alimentação escolar e constituição de identidades dos escolares: da merenda para pobres ao direito à alimentação. Cad. Saúde Pública, Rio de Janeiro, v. 34, n. 2, p. e001426117, 2018. DOI: https://doi.org/10.1590/0102-311x00142617.

TURPIN, M. H. A alimentação escolar como vetor de desenvolvimento local e garantia de segurança alimentar e nutricional. 2008. (Dissertação) - Universidade Estadual de Campinas, Campinas, 2008.

VASCONCELOS, F. A. G. Programa Nacional de Alimentação Escolar: limites e possibilidades para a garantia do direito humano à alimentação adequada, saudável e sustentável. Ciênc. Saúde Coletiva, Rio de Janeiro, v. 18, n. 4, p. 906, abr. 2013. http://dx.doi.org/10.1590/S141381232013000400001.

ZURAYK, R. Pandemic and food security: a view from the Global South. JAFSCD, Ithaca, v. 9, n. 3, p. 17-21, 2020. DOI: https://doi.org/10.5304/jafscd.2020.093.014. 